\title{
The effects of mindful attention on cold pressor pain in children
}

\author{
Mark Petter $\mathrm{BA}^{1,2}$, Christine T Chambers $\mathrm{PhD}^{1,2,3,4}$, Jill MacLaren Chorney $\mathrm{PhD}^{1,2,5}$
}

\begin{abstract}
M Petter, CT Chambers, J MacLaren Chorney. The effects of mindful attention on cold pressor pain in children. Pain Res Manag 2013;18(1):39-45.
\end{abstract}

BACKGROUND: Typical interventions for acute pain in children attempt to reduce pain by directing attention away from pain. Conversely, mindfulness involves devoting attention to one's experience in an accepting and nonjudgmental way. However, the effect that instructing children to mindfully devote attention to acute pain has on pain outcomes is unknown.

OBJECTIVES: To examine whether mindful attention can help children attend to pain without increasing pain intensity or decreasing pain tolerance; to compare the effects of mindful attention with a well-established intervention designed to take attention away from pain (guided imagery); and to test whether baseline coping style or trait mindfulness alter the effects of these interventions.

METHODS: A total of 82 children (10 to 14 years of age) completed measures of coping style and trait mindfulness. Participants then received either mindful attention or guided imagery instructions designed to direct attention toward or away from pain, respectively, before participating in a cold pressor task.

RESULTS: The mindful attention group reported more awareness of the physical sensations of pain and thoughts about those sensations. Overall, there were no between-group differences in measures of pain intensity or pain tolerance during the cold pressor task, and no evidence of an interaction between baseline characteristics of the child and experimental condition. CONCLUSIONS: Mindful attention was successful in helping children focus attention on experimental pain without increasing pain intensity or decreasing tolerance compared with a well-established intervention for acute pain reduction.

Key Words: Attention; Children; Guided imagery; Mindfulness; Pain

\author{
Les effets de la pleine conscience de la douleur \\ causée par l'épreuve au froid chez les enfants
}

HISTORIQUE : Les interventions habituelles relatives à la douleur aiguë chez les enfants visent à réduire la douleur en détournant l'attention de cette douleur. Par contre, la pleine conscience consiste à porter attention à une expérience avec acceptation et sans jugement. Cependant, on ne sait pas quel serait l'effet de demander aux enfants d'avoir une pleine conscience de la douleur sur les issues de leur douleur.

OBJECTIFS : Examiner si la pleine conscience aiderait les enfants à réagir à la douleur sans en accroître l'intensité ou en réduire l'intolérance, comparer les effets de la pleine conscience à une intervention bien établie conçue pour détourner l'attention de la douleur (imagerie orientée) et vérifier si le style d'adaptation ou les caractéristiques de pleine conscience de départ modifient les effets de ces interventions.

MÉTHODOLOGIE : Quatre-vingt-deux enfants (de dix à 14 ans) ont fourni des mesures sur le style d'adaptation et les caractéristiques de pleine conscience. Ils ont ensuite reçu des directives sur la pleine conscience ou l'imagerie orientée conçue pour concentrer leur attention sur la douleur ou la détourner de la douleur, respectivement, avant de participer à une tâche d'épreuve au froid.

RÉSULTATS : Le groupe de pleine conscience se disait plus sensible aux sensations physiques de la douleur et aux pensées liées à ces sensations. Dans l'ensemble, les chercheurs n'ont remarqué aucune différence entre les groupes pour ce qui est des mesures d'intensité de la douleur ou de tolérance à la douleur pendant l'épreuve au froid, ni de manifestations d'interaction entre les caractéristiques de départ de l'enfant et la situation expérimentale. CONCLUSIONS : La pleine conscience a réussi à aider les enfants à concentrer leur attention sur la douleur sans accroitre l'intensité de la douleur ou réduire la tolérance par rapport à une intervention bien établie de réduction de la douleur aiguë. ttention-based coping strategies are widely used in the manage-
ment of children's pain. Techniques designed to shift children's
attention away from a painful event and toward a competing stimulus,
such as distraction, are considered to be well-established interventions
for acute pain in children (1). These types of interventions have been
found to reduce children's pain in a number of contexts, including
experimental pain (2,3), needle-related medical procedures $(4,5)$, and
pain following injury (6) and during acute somatic complaints (7). As
such, they are also included in most cognitive behavioural therapy
interventions for chronic pain ( 8 ).
While distraction-based interventions that direct attention away
from a painful experience work well for most children, effect sizes are
typically small to moderate (9), and outcomes are heterogeneous
across settings and method of delivery. Recent research has even sug-
gested that some types of distraction may increase pain among chil-
dren who tend to catastrophize about pain (10). Sensory-focused
techniques are an alternative attention-based coping strategy that
involves focusing on the physical sensations of pain in an objective
manner. Among older children (older than 10 years of age), these
types of interventions have been found to be as effective as distraction-
based interventions ( 3 ). Studies have shown that among children who do not typically use distraction to cope with pain, interventions designed to shift their attention toward pain in an adaptive manner are also more beneficial (3). The finding that interventions that are 'matched' with coping style (eg, using distraction with a child who typically uses distraction when they are in pain) are the most effective is known as the 'congruence hypothesis' (11).

Although focusing attention on pain may appear to be counterintuitive, it has been argued that attending to pain nonjudgmentally may interrupt the sensation-distress associations (12). In addition, these sensory-focused techniques share a number of similarities with the present-moment awareness encouraged in mindfulness-based interventions (13). 'Mindfulness' refers to a state of consciousness that involves purposefully attending to moment-to-moment experience in a nonjudgmental and accepting manner (13-15). Mindfulness may be viewed as a trait (ie, the tendency to be mindful across time) as well as a state $(14,15)$. Evidence shows that standard mindfulness programs (13) that include daily mindfulness practice are beneficial for adults, including those with chronic pain (16). Research has also shown that more brief mindfulness-based interventions (performed over several days) can alter acute experimental pain outcomes, such as pain intensity (17) and pain tolerance (18) among adults, and

Department of ${ }^{1}$ Psychology, Dalhousie University; ${ }^{2}$ Centre for Pediatric Pain Research, IWK Health Centre; Departments of ${ }^{3}$ Pediatrics,

${ }^{4}$ Psychiatry and ${ }^{5}$ Anesthesiology, Dalhousie University, Halifax, Nova Scotia

Correspondence: Mr Mark Petter, Department of Psychology, Dalhousie University, Life Sciences Centre, 1355 Oxford Street, Halifax,

Nova Scotia B3H 4J1. Telephone 902-470-6906, fax 902-470-7118, e-mail mark.petter@dal.ca 


\begin{tabular}{|c|c|c|}
\hline & $\begin{array}{l}\text { Mindfulness-based } \\
\text { attention }(n=42)\end{array}$ & $\begin{array}{l}\text { Guided imagery } \\
\qquad(n=40)\end{array}$ \\
\hline \multicolumn{3}{|l|}{ Child characteristics } \\
\hline Age, years & $12.38 \pm 1.23$ & $11.63 \pm 1.50^{*}$ \\
\hline Male sex, n (\%) & $27(64)$ & $19(48)$ \\
\hline Caucasian, n (\%) & $36(86)$ & $32(80)$ \\
\hline Distraction coping style (0-5) & $3.33 \pm 0.73$ & $3.29 \pm 0.73$ \\
\hline Trait mindfulness (0-40) & $23.31 \pm 5.54$ & $23.40 \pm 6.27$ \\
\hline \multicolumn{3}{|l|}{ Parent characteristics } \\
\hline Age, years & $41.40 \pm 5.72$ & $42.28 \pm 5.19$ \\
\hline $\begin{array}{l}\text { Relationship to child (mother), } \\
\mathrm{n}(\%)\end{array}$ & $37(88)$ & $35(88)$ \\
\hline Marital status (married), n (\%) & $27(64)$ & $25(63)$ \\
\hline Education (postsecondary), n (\%) & $33(79)$ & $33(83)$ \\
\hline Total number of children & $2.55 \pm 1.23$ & $2.58 \pm 1.06$ \\
\hline
\end{tabular}

Data presented as mean \pm SD unless otherwise indicated. Distraction coping style is based on a combination of the behavioural and cognitive subscales from the Pain Coping Questionnaire (24). Trait mindfulness is based on the total score from the Childhood Acceptance and Mindfulness Measure (25). ${ }^{*}<<0.05$

these interventions compare favourably with distraction and guided imagery $(17,18)$.

Despite growing interest in the use of mindfulness with children $(19,20)$, there is little research examining the effects of mindfulnessbased interventions on pain in this population. Furthermore, there is no research examining the effect of instructions to mindfully attend to pain among children. However, given that it shares some similarities with sensory-focused techniques, it appears that instructions that help children mindfully devote attention to painful physical sensations may reduce the subjective experience of pain and promote tolerance. Specifically, by maintaining an objective awareness of bodily sensations while adopting a nonjudgmental and accepting attitude toward thoughts and emotions that arise during a painful experience, children may be able to lessen the impact of some of the negative thoughts and emotions that can cause increases in pain intensity (21). However, it is not known whether the use of mindful attention offers any benefit compared with more traditional attention-based interventions designed to take attention away from a painful event (ie, distraction).

The present study, therefore, had three main objectives. The first was to evaluate whether a novel mindful attention intervention could help children devote attention mindfully to pain during an experimental pain task. It was hypothesized that, if this intervention was successful, it would increase attention to the physical sensations as well as thoughts about those sensations without increasing pain intensity or decreasing tolerance during an experimental pain task, relative to a distraction-based intervention. Furthermore, given that the purpose of mindful attention was to increase objectivity concerning internal experience (15), it was hypothesized that the amount of time spent attending to physical sensations as well as thoughts about those sensations would be related to pain intensity in the distraction-based condition but not the mindful attention condition. The second objective was to compare the effects of the mindful attention intervention with an intervention designed to shift attention away from pain on pain outcomes during an experimental pain task. Guided imagery was selected for comparison because it is widely used, has a strong evidence base and would provide approximately equivalent amounts of detail in instruction during the intervention (1). Because of mixed findings in this field comparing interventions that direct attention toward and away from the physical sensations of pain (2,3), no directional hypothesis was made between the two groups. However, because the purpose of the guided imagery was to direct attention away from the physical sensations of the pain task, it was hypothesized that the amount of time devoted to attending to physical sensations and thoughts about those sensations would be significantly associated with pain intensity in this group. The final objective was to explore the congruence hypothesis by evaluating whether baseline characteristics (coping style, trait mindfulness) interacted with experimental condition to predict pain outcomes. Based on previous studies in the field $(2,3)$, it was hypothesized that instructions that 'matched' baseline coping style would be most effective; ie, children who were high in trait mindfulness would have better outcomes when they received the mindful attention instructions, and children who scored high on a measure of baseline distraction-based coping would do better when they received the guided imagery.

\section{METHODS}

\section{Design}

The present study used a randomized between-subjects design. Participants were randomly assigned to listen to either mindful attention or guided imagery condition before and during the time that they participated in an experimental pain task (cold pressor task [CPT]).

\section{Participants}

Eighty-six healthy children between 10 and 14 years of age with no history of chronic pain were recruited from the community through advertisements and word of mouth. Of these 86 children, three were excluded from the final analysis because they put their hand into the cold pressor too early (before instructed to do so), and one was excluded because he/she was unable to read/understand the questionnaires. The final sample of 82 children had a mean $( \pm$ SD) age of $12.01 \pm 1.41$ years, and was predominantly Caucasian $(83 \%)$, male (56\%) and had $1.56 \pm 1.15$ siblings. Parents who accompanied the children were predominantly Caucasian (88\%), married $(63 \%)$, and mothers (88\%) with some form of postsecondary education $(81 \%)$ and a mean age of $41.84 \pm 5.43$ years. Demographic information for the experimental groups can be found in Table 1 .

\section{Apparatus}

Cold pressor: The CPT is a valid and ethically acceptable experimental technique for inducing pain in humans that has been widely used with children $(22,23)$. The device used in the present study consisted of a $26.5 \mathrm{~L}$ commercially produced plastic cooler, measuring $23.5 \mathrm{~cm}$ in width, $43.5 \mathrm{~cm}$ in length and $28.0 \mathrm{~cm}$ in height, with an opening in the top $(11 \mathrm{~cm}$ in diameter). The cooler was filled with cold water $\left(10 \pm 1^{\circ} \mathrm{C}\right)$ and was fitted with a thermometer and pump that circulated water and maintained a constant temperature consistent with standard CPT procedures for children (23).

Video equipment: Two digital surveillance-type cameras (model number VCC-9000INC/INS, Sanyo, Japan) that streamed video and audio directly to a digital video recorder (model number DSR-M800, Sanyo, Japan) were used to record the CPT and pain tolerance times. The cameras were placed in two opposite corners of the testing room. One camera was positioned near the ceiling directly facing the participant (allowing for a frontal view), and the other camera was positioned near the ceiling to the right of the participant (allowing for a side view).

Audio equipment: A compact disc (CD) player (model number RCD330-B, RCA, USA) was used to play the audio CDs. The CD player was placed on a $40 \mathrm{~cm}$ high table, $120 \mathrm{~cm}$ in front of the participant. Audio was played over the CD player's speakers.

\section{Instructions}

Guided imagery condition: Participants in this condition listened to an audio CD that instructed them in a standard guided imagery scene designed to focus their attention away from the CPT. Participants were first instructed to breathe deeply and try to relax. Before beginning the $\mathrm{CPT}$, the CD instructed children that they were going to imagine themselves walking along a beach on a pleasant summer day for approximately $10 \mathrm{~min}$. The instructions were designed to engage children in the feelings (eg, sand flowing through fingers), sights (eg, a lighthouse), smells (eg, the ocean) and sounds (eg, birds in the 
distance) that would be encountered on a trip to the beach. After this initial practice image, the $\mathrm{CD}$ gave children a brief set of instructions on the administration of the CPT. Leading up to and during the administration of the CPT, children were instructed by the audio recording to once again imagine themselves in the same beach scene they had just practiced. This guided imagery scene is similar to those used in previous studies (3).

Mindful attention condition: Participants in the mindful attention condition listened to an audio CD (also approximately $10 \mathrm{~min}$ in length) with instructions designed to focus their attention in a nonjudgmental manner on the physical sensations of the CPT as well as thoughts that may arise during the CPT. The same person recorded the mindful attention instructions and the guided imagery instructions. Before beginning the CPT, the CD instructed participants to notice how their whole body felt and to bring their attention to the sensations of breathing. Children were instructed not to try to change what they were feeling, but to simply notice how their experience changed from moment to moment. The CD then instructed participants to focus their attention on their dominant arm (the one they would not use in the CPT) and to notice the sensations in that arm. They also received instructions on observing the thoughts they may experience during the task. Children were instructed to notice thoughts that may distract them while focusing their attention on their arm, to be accepting of those thoughts, (even if those thoughts were upsetting, such as "this is hard"), to let go of thoughts after they noticed them, and to gently bring their attention back to their arm. After initially practicing this mindful attention, the audio recording gave children a brief set of instructions regarding the CPT. Leading up to and during the administration of the CPT, children were instructed by the audio recording to devote attention to the physical sensations in the arm that was placed in the cold water, and to notice, accept and let go of thoughts that may arise during the CPT. This script was developed by the authors with the purpose of incorporating important components of mindfulness, such as moment-to-moment awareness (eg, "Think of yourself as scientist trying to discover what is happening in your body and mind at each moment"), and an attitude of nonjudgement and acceptance (eg, "Just notice these thoughts, thank your mind for having them, and go back to paying attention to your arm") (13). This intervention was designed to be consistent with standard mindfulnessmeditation techniques (13), while also incorporating aspects of mindfulness interventions designed for children (19).

\section{Measures}

Coping style: The child version of the Pain Coping Questionnaire (PCQ [24]) was used to assess children's baseline coping style. The PCQ is a self-report measure designed to assess how a child typically copes with pain. Children are asked to rate how often they say, think or do certain things when they are in pain. The PCQ yields eight subscales (including information seeking, behavioural distraction, cognitive distraction and internalizing/catastrophizing). Consistent with previous literature in this area $(2,3)$, an overall distraction coping style subscale was calculated by combining the cognitive and behavioural distraction subscales. In the present study, this distraction coping style subscale had a high internal consistency $(\alpha=0.88)$.

Trait mindfulness: The Childhood Acceptance and Mindfulness Measure (CAMM [25]) was used to measure trait mindfulness. The CAMM is a 10 -item self-report measure designed to assess the extent to which children observe internal experiences, act with awareness and accept internal experiences without judgment. The CAMM yields a total score of trait mindfulness ranging from 0 to 40, with higher scores indicating higher levels of trait mindfulness. The CAMM has been validated in children older than nine years of age (24). In the present study, the CAMM showed adequate internal consistency $(\alpha=0.74)$.

Pain tolerance: During the CPT, pain tolerance was measured as the time (in s) elapsed from when the child's hand and forearm were immersed in the water to the time it was voluntarily removed, up to a maximum of $4 \mathrm{~min}(240 \mathrm{~s})$.
Pain intensity: The Faces Pain Scale-Revised (FPS-R [26]) was used to measure the average and the most severe pain experienced during the CPT. Participants were asked to choose the face that corresponded most closely to the average and worst pain they felt during the CPT from a series of six faces. The FPS-R has strong psychometric properties and is a widely used measure of subjective pain in children.

Attentional direction and evaluation of instructions: For the purposes of the present study, the authors developed a series of questions designed to examine the direction of children's attention toward or away from the physical sensations and thoughts about those sensations during the CPT. Children were asked to answer how often their attention was directed toward the physical sensations they experienced (ie, "How often did you notice how your arm felt?"), as well as the thoughts about those sensations (ie, "How often did you notice the thoughts you were having about your arm?") and away from what they were experiencing (ie, "How often did you imagine you were somewhere else?") during the CPT. In addition, children were asked to indicate how often they became distracted from the $\mathrm{CD}$, whether they believed the CD was helpful, how often they wanted to take their arm out of the water and whether they would use the strategies they had learned on the $\mathrm{CD}$ in the future. Answers were provided on a 5-point Likert scale ranging from 1 'not at all' to 5 'always'.

\section{Procedure}

The present study was conducted in a research centre within a larger tertiary children's health care institution and was approved by the Institutional Research Ethics Board. Parents and children provided informed written consent and assent before participating in the study. Parents were informed that their children would be participating in the CPT and that they would be listening to one of two CDs while doing so. Children were not given any information regarding the content of the CD. Children were informed that they would be in the testing room by themselves, but that the researcher and their parent(s) would be able to view them on the video cameras in an adjacent room. It was emphasized to children that it was important to listen to the instructions on the CDs because the purpose of the study was to determine whether they helped children during the CPT. After this brief explanation of the study, children were asked to complete the PCQ, followed by the CAMM, while their parents completed a demographic questionnaire. After completing the questionnaires, children went to the testing room and sat in a chair next to the CPT. Parents were told they could stand by the door to see the testing room while the child was given instructions. Once again the CPT was explained to the participants. Specifically, participants were told that the $\mathrm{CD}$ would play for approximately $10 \mathrm{~min}$ and ask them to do a number of things. Eventually, the CD was going to ask them to put their hand in the water up to their wrist and continue to try and do the things they had been practicing before. Participants were told that when they put their hand in the water that they were to keep it in for as long as they could, even if it was uncomfortable, but if it became too uncomfortable or hurt too much that they could remove it. They were also informed that after 4 min the CD would tell them to remove their hand from the water if it was still in. The research assistant then started the audio recording and left the room. The CD guided the participant to practice either the mindful attention or guided imagery, and instructed them when to place their hand in the water and when the 4 min time limit had been reached. Both CDs played before and during the time that the children placed their hand in the water. Children were observed by the research assistant and their parent on a closed-circuit video system while they participated. After children removed their hand from the water, or the 4 min time limit was reached, the research assistant immediately returned to the testing room and had the child complete the FPS-R. Children were then given a cloth to dry their hand and asked to complete the questionnaire concerning attentional direction and evaluation of the CD. After completing these, the researcher answered any final questions from the children and parents. Families were then thanked for their 
TABLE 2

Pearson correlation matrix among baseline characteristics and pain outcomes

\begin{tabular}{lcccc}
\hline & $\mathbf{1}$ & $\mathbf{2}$ & $\mathbf{3}$ & $\mathbf{4}$ \\
\hline 1. Distraction coping style & - & -0.124 & -0.062 & -0.189 \\
2. Trait mindfulness & & - & 0.044 & 0.117 \\
3. Average pain & & & - & $0.792^{\star}$ \\
4. Worst pain & & & & - \\
\hline
\end{tabular}

Distraction coping style is based on a combination of the behavioural and cognitive subscales from the Pain Coping Questionnaire (24). Trait mindfulness is based on the total score from the Childhood Acceptance and Mindfulness Measure (25). Average and worst pain are based on The Faces Pain ScaleRevised (26). ${ }^{*} P<0.001$

participation and given a small monetary compensation ( $\$ 15$ for children and $\$ 5$ for parents).

Data analytic plan

A sensitivity analysis, based on a sample size of $82, \alpha=0.05$ and power $=0.80$, was performed for the main effect and interactions of a one-way, between-subjects ANCOVA with one covariate. Results indicated that the study was adequately powered to detect a medium effect size $(f=0.31)$

Before beginning analysis, the data set was checked for completeness. Several individual items on the CAMM had been missed by a number of participants ( $1.5 \%$ of total item responses to the questionnaire). A nonsignificant Little's Missing Completely At Random test $\left(\chi^{2}=231.69 ; \mathrm{P}=0.17\right)$ revealed that data were missing completely at random. When data are missing completely at random and a small portion of the data are missing, a single imputation using the expectation maximization algorithm provides unbiased parameter estimates and improves statistical power of analyses (27). Therefore, this method was used to impute the missing data.

Because so many children reached the time limit with regard to the pain tolerance measure (guided imagery $72 \%$, mindful attention $81 \%$ ), the outcome measure of pain tolerance was dichotomized as either having reached time limit (1) or not (0).

Between-group comparisons using one-way, between-subjects ANOVA and $\chi^{2}$ analysis were initially conducted to determine whether the two experimental groups differed in any baseline characteristics that may need to be controlled for in future analysis. Pearson's correlation analysis and $\chi^{2}$ analysis were then conducted to examine whether baseline characteristics were related to the pain outcome measures. Because age was found to differ significantly between groups and is a known covariate of experimental pain outcomes (3), it was controlled for in further analyses.

The first hypothesis, that groups would differ on measures of attention, was tested using a series of one-way, between-subjects ANCOVAs, controlling for initial baseline demographic differences (age) between the two experimental groups on the measures of attentional direction. Within each group, a Pearson's partial correlation (controlling for age) was then used to examine the relationship between attentional direction and pain intensity. Finally, a series of one-tailed Fisher's $z$ analyses were used to examine the hypothesis that noticing the feelings in their arm as well as their thoughts about those feelings would be more strongly related to pain intensity for children in the guided imagery group than the mindful attention group.

To examine the influence of experimental group on pain outcomes, a series of one-way, between-subjects ANCOVAs were used to examine group differences in pain intensity, and $\chi^{2}$ analyses were used to compare the pain tolerance outcomes between the groups.

Finally, to test the congruence hypothesis of pain interventions, a series of 2 (experimental group) $\times 2$ (median split of distraction coping style/trait mindfulness) ANCOVAs, controlling for child's age, were conducted on the intensity measures to examine whether baseline characteristics interacted with experimental condition to predict average or worst pain reported pain. To test the interaction effects of
TABLE 3

Direction of attention and evaluation of the recorded instructions according to group

\begin{tabular}{lcc}
\hline How often did you... & $\begin{array}{c}\text { Mindfulness- } \\
\text { based attention }\end{array}$ & Guided imagery \\
\hline ...notice the feelings in your arm? & $4.24 \pm 0.73$ & $3.60 \pm 1.01^{\star \star}$ \\
...notice your thoughts about your arm? & $3.86 \pm 0.87$ & $3.00 \pm 1.12^{\star * \star}$ \\
...imagine you were somewhere else? & $1.88 \pm 1.04$ & $3.22 \pm 1.21^{\star \star *}$ \\
... want to take your arm out of the water? & $3.10 \pm 1.10$ & $2.40 \pm 1.12^{\star}$ \\
...become distracted from the CD? & $2.64 \pm 1.01$ & $2.85 \pm 1.15$ \\
How helpful was the CD? & $3.29 \pm 1.20$ & $3.00 \pm 1.18$ \\
Would you use the strategy again? & $3.38 \pm 1.06$ & $3.30 \pm 1.09$ \\
\hline
\end{tabular}

Data are presented as mean $\pm S D$. Scores on each question are evaluated on a 5-point Likert scale, with higher scores indicating how often the statement was true for them. Estimates of significance are based on one-way ANCOVAs with age as a covariate. ${ }^{\star} P<0.05,{ }^{* *} P<0.01,{ }^{* * *} P<0.001$. CD Compact disc

baseline characteristics and experimental group on pain tolerance, a series of logistic regression analyses were conducted. Centred baseline characteristics and experimental group were entered in step 1 , and the interaction term of these variables was entered in step 2 .

\section{RESULTS}

Baseline characteristics between groups and association with pain outcomes

Baseline characteristics of participants are presented in Table 1. Children in the mindful attention condition were significantly older than children in the guided imagery condition $(F[1,80]=6.27$; $\mathrm{P}<0.05)$. Groups did not differ in any other demographic variables. There were no significant group differences in any of the baseline measures of distraction-based coping style or trait mindfulness. No baseline demographic characteristics, including distraction-based coping style or trait mindfulness, were related to outcome measures of pain intensity or pain tolerance. Table 2 presents the correlations among baseline coping style, trait mindfulness and pain intensity.

\section{Attentional direction between groups}

The means and SDs for children's self-reported attention and perceived effectiveness of instructions are presented in Table 3. After controlling for age, children in the mindful attention condition reported that they noticed how their arm felt in the water $\left(\mathrm{F}[1,79]=10.44, \eta_{\mathrm{p}}{ }^{2}=0.12 ; \mathrm{P}<0.01\right)$, noticed the thoughts they were experiencing about their arm $\left(F[1,79]=12.36, \eta_{p}{ }^{2}=0.14 ; P<0.001\right)$ and wanted to take their arm out of the water $(F[1,79]=6.23$, $\left.\eta_{\mathrm{p}}{ }^{2}=0.07 ; \mathrm{P}<0.05\right)$ significantly more than the guided imagery group. Conversely, the guided imagery group reported that they imagined they were somewhere else significantly more $(F[1,79]=24.06$, $\left.\eta_{\mathrm{p}}{ }^{2}=0.23 ; \mathrm{P}<0.001\right)$ than the mindful attention group. There was no significant group difference on how often children reported being distracted from the audio recording $\left(F[1,79]=1.14, \eta_{p}{ }^{2}=0.01 ; P=0.29\right)$, how much they believed the CD helped them keep their arm in the water $\left(F[1,79]=1.45, \eta_{p}{ }^{2}=0.02 ; P=0.23\right)$, or how likely they would be to use the skills they had learned if they had to do something painful in the future $\left(F[1,79]=0.04, \eta_{p}^{2}=0.00 ; P=0.85\right)$.

\section{Attentional direction and pain intensity according to group}

Partial correlations among attentional direction and pain outcomes by groups are presented in Table 4. For the guided imagery group, noticing how their arm felt in the water as well as noticing thoughts about their arm were significantly associated with average pain and worst pain. How often children reported imagining they were somewhere else was unrelated to pain intensity. For the mindful attention group, noticing how their arm felt in the water was associated with average and worst pain. Noticing thoughts about their arm and imagining they were somewhere else was unrelated to pain intensity. Groups did not differ in the magnitude of association between noticing how their arm felt and 
average pain $(z=0.22 ; \mathrm{P}=0.41)$ or worst pain $(z=-0.10 ; \mathrm{P}=0.46)$. However, there was a significant difference in association between noticing their thoughts with average pain $(z=-1.76 ; \mathrm{P}<0.05)$ and a borderline relationship for worst reported pain $(z=-1.63 ; \mathrm{P}=0.052)$ in that the magnitude of correlation was significant in the guided imagery group and there was no association in the mindful attention group.

\section{Pain outcomes by group}

After controlling for age, there was no significant difference between the guided imagery and the mindful attention condition on average (guided imagery $3.18 \pm 2.06$, mindful attention $3.98 \pm 1.89, F[1,79]=3.24$, partial $\eta_{\mathrm{p}}{ }^{2}=0.04 ; \mathrm{P}=0.08$ ) or worst reported pain (guided imagery $5.73 \pm 2.45$, mindful attention $6.43 \pm 2.00, \mathrm{~F}[1,79]=2.12$, partial $\left.\eta_{\mathrm{p}}{ }^{2}=0.03 ; \mathrm{P}=0.15\right)$.

Because so many children reached the time limit with regard to the pain tolerance measure (guided imagery $72 \%$, mindfulness-based attention $81 \%$ ), the outcome measure of pain tolerance was dichotomized as either having reached the time limit or not. A $\chi^{2}$ analysis on this dichotomized outcome showed that there was no effect of experimental condition on whether children left their arm in the water for the full amount of time $\left(\chi^{2}[1]=0.82 ; \mathrm{P}=0.44\right)$.

Interaction between baseline characteristics, experimental condition and pain intensity

A series of 2 (mindful attention/guided imagery instructions) $\times 2$ (median split of distraction coping style/trait mindfulness) ANCOVAs, controlling for child's age, were conducted on the intensity measures to determine whether baseline characteristics interacted with experimental condition to predict average or worst pain. There was no significant interaction between distraction coping style and experimental condition on average pain $\left(F[1,77]=0.166, \eta_{\mathrm{p}}{ }^{2}=0.00 ; \mathrm{P}=0.69\right)$ or worst pain $\left(F[1,77]=0.59, \eta_{p}{ }^{2}=0.01 ; P=0.45\right)$. There was also no significant interaction between trait mindfulness and experimental condition on average pain $\left(\mathrm{F}[1,77]=0.39, \eta_{\mathrm{p}}{ }^{2}=0.01 ; \mathrm{P}=0.54\right)$ or worst pain $\left(\mathrm{F}[1,77]=1.00, \eta_{\mathrm{p}}{ }^{2}=0.01 ; \mathrm{P}=0.32\right)$.

A hierarchical logistic regression analysis showed that the interaction term of experimental condition and distraction-based coping was not a significant predictor of whether a child left their arm in the water for the full $4 \mathrm{~min}(\beta=-0.97, \mathrm{SE}=0.73 ; \mathrm{P}=0.19)$ after controlling for child's age, and the main effects of experimental condition and distraction-based coping. In addition, the interaction between experimental condition and trait mindfulness was also not a significant predictor of pain outcomes $(\beta=0.03, \mathrm{SE}=0.10 ; \mathrm{P}=0.73)$ after accounting for these variables.

\section{DISCUSSION}

The purpose of the present study was to examine the effects of mindful attention on acute pain in children. Our first objective was to examine whether mindful attention instructions could increase attention to physical sensations and thoughts during a pain task without increasing pain intensity or decreasing tolerance. We hypothesized that these instructions would result in children devoting more attention to the sensations in their arm as well as their thoughts about those sensations. We also hypothesized that paying attention to their arm and the thoughts about their arm would be unrelated to pain outcomes for children in the mindful attention group. These hypotheses were based on the belief that, by maintaining an objective awareness of bodily sensations and cognitions while adopting a nonjudgmental and accepting attitude, children may lessen the impact of negative thoughts and emotions that can cause increases in pain intensity (21). Results related to this first objective were mixed. As expected, children in the mindful attention group reported noticing the feelings in their arm and thoughts about their arm more often than the guided imagery group. Furthermore, in the guided imagery condition, being aware of thoughts about the physical sensations of the pain task was significantly related to pain intensity, while this was not the case in the mindful attention group. These findings appear to offer some support for the theory that mindfulness-based interventions may lead to a
TABLE 4

Association between direction of attention and pain outcomes according to group

\begin{tabular}{llccccc}
\hline & \multicolumn{5}{c}{ Mindfulness-based attention } \\
\cline { 2 - 6 } & $\mathbf{1}$ & $\mathbf{2}$ & $\mathbf{3}$ & $\mathbf{4}$ & $\mathbf{5}$ \\
\hline 1. Notice arm & - & $0.448^{* *}$ & -0.196 & $0.375^{*}$ & $0.329^{*}$ \\
2. Notice thoughts & & - & -0.142 & 0.167 & 0.127 \\
3. Imagine you were somewhere else & & & - & 0.266 & 0.253 \\
4. Average pain & & & & - & $0.813^{\star * *}$ \\
5. Worst pain & & & & & &
\end{tabular}

5. Worst pain

\begin{tabular}{lccccc} 
& \multicolumn{5}{c}{ Guided imagery } \\
\cline { 2 - 6 } & $\mathbf{1}$ & $\mathbf{2}$ & $\mathbf{3}$ & $\mathbf{4}$ & $\mathbf{5}$ \\
\hline 1. Notice arm & - & $0.464^{\star *}$ & -0.011 & $0.331^{*}$ & $0.349^{\star}$ \\
2. Notice thoughts & & - & 0.133 & $0.517^{\star * *}$ & $0.463^{\star *}$ \\
3. Imagine you were somewhere else & & & - & 0.006 & 0.028 \\
4. Average pain & & & & - & $0.767^{\star * *}$ \\
5. Worst pain & & & & & - \\
\hline
\end{tabular}

Variables 1-3 were from the self-report measure of attentional direction. Notice arm = "How often did you notice the feelings in your arm?"; Notice thoughts = "How often did you notice your thoughts about your arm?"; Imagine you were somewhere else = "How often did you imagine you were somewhere else?" Average and worst pain are based on scores from the Faces Pain Scale-Revised (26). ${ }^{*} P<0.05,{ }^{* *} P<0.01,{ }^{*} * * P 0.001$. Estimates of significance are based on Pearson's partial correlations controlling for age

change in the relationship that an individual has with their thoughts, such that they are regarded as mental events rather than necessarily true reflections of what is actually happening (see Grabovac et al [28] for a review of several models of mindfulness). This finding is of particular interest given the belief held by many researchers and clinicians that this type of shift in the relationship with internal experience requires lengthy training in mindfulness, rather than the brief mindful attention instructions used in the present study.

Contrary to our hypothesis, noticing the physical sensations in their arm was related to pain intensity in both the mindful attention and guided imagery group. This was expected in the imagery group, where noticing the physical sensations of their arm was contrary to the intervention being used, but was unexpected in the mindful attention group. However, this is consistent with some research conducted on adults that has shown that the greatest effects of mindfulness are on cognitive reactions to pain, rather than on the physical sensations of pain (28). The unexpected finding that children in the mindful attention condition wanted to take their arm out of the water more often may also be interpreted within this framework. It has been argued that mindfulness should lead to greater awareness and self-regulation in that an individual is able to have thoughts and emotions without reacting habitually to them (15). In this case, having children become aware of thoughts as they arose during the CPT may have increased awareness of thoughts, such as "I want to take my arm out of the water", but helped increase self-regulation so that they did not have to habitually react to them. Again this could be interpreted as an example of children noticing thoughts as mental events rather than accurate reflections of reality that must be acted on.

Our second objective was to compare the effects of this novel mindful attention intervention to guided imagery on pain outcomes. Results showed no significant differences between the two groups on measures of pain intensity or tolerance. The experimental condition accounted for a small amount of variation in pain intensity (less than $4 \%$ ), and pain tolerance was equivalent across groups. These results can be interpreted with cautious optimism in terms of the use of mindful attention instructions for acute pain, when considering that the comparison group was a well-established psychological intervention for reducing pain in children (1). It should be noted that, given the high tolerance of the experimental pain task and the lack of a notreatment control group, these conclusions need to be interpreted with 
caution. Overall, $77 \%$ of children in the study were able to leave their arm in the water for the full $4 \mathrm{~min}$, which limited the use of parametric tests. This was unexpected because a recent review of pediatric CPT research using $10 \pm 1^{\circ} \mathrm{C}$ water indicated that between $20 \%$ to $50 \%$ of children typically reach the 4 min ceiling (29). Furthermore, $10 \pm 1^{\circ} \mathrm{C}$ is the most common temperature used in pediatric research (22) and is suggested in current guidelines for using the CPT with children (23). Based on these findings, we speculate that both interventions may have helped children tolerate the pain experienced during the CPT. The decision not to include a no-treatment condition was made on the assumption that comparable outcomes between the two groups would be an indication of the success of the mindful attention intervention (given the strong evidence for the use of guided imagery). However, given our lack of power to detect small between-group differences, future research comparing mindful attention interventions with no-treatment control conditions are also warranted.

Our third and final objective was to test the 'congruence hypothesis' of pain interventions. It was predicted that children would benefit more if they received an intervention that was consistent with their baseline coping style. The results did not support our hypothesis; there was no interaction between distraction-based coping or trait mindfulness with experimental condition on pain outcomes, and less than $1 \%$ of the total variance in pain intensity was accounted for by the interaction between baseline characteristics and experimental condition. These results are inconsistent with some previous research using the CPT that has found that interventions that are matched to coping style are the most effective $(2,3)$. However, further examination of the literature on the congruence hypothesis reveals less consistency. For example, while Fanurik et al (2) found that children who were 'distractors' (ie, they naturally used distraction when in pain) at baseline benefitted more from a distraction intervention, this congruence effect was not observed among children classified as 'attenders'. Furthermore, Piira et al (3) found evidence that a sensory-focus intervention increased pain tolerance among children low in distraction-based coping, but this was not the case for children high in distraction-based coping, or on pain intensity measures. Certainly, more research is required in this area to draw strong conclusions regarding how baseline coping style interacts with interventions to predict pain outcomes.

There are several potential limitations that need to be taken into account when interpreting these results. First, participants volunteered to participate in a study on pain, which may have resulted in a selection bias because children who have poor pain coping or are highly anxious about pain would be unlikely to volunteer. Furthermore, children were also informed that the pain experience would be timelimited, which may have led to lower distress than would be encountered in a clinical context. Children who participated were also generally healthy, and further research is needed to understand the effects of this type of intervention on clinical populations. In addition, although the mindful attention instructions appeared to be successful in manipulating attention during the experimental pain task, future research is needed to explicitly examine how these types of interventions affect other potentially important aspects of mindfulness such as nonjudgment and nonreactivity toward personal experience. Finally, many models explaining the underlying mechanisms of mindfulness (28) would emphasize how mindfulness-based interventions may alter the emotional and cognitive aspects of the pain experience (eg, catastrophic thoughts, emotional distress due to pain), rather than the physical components of pain measured in the present study. Future research in this field should take care to examine whether mindful attention alters these emotional and cognitive responses to pain in addition to typical pain outcomes.

Despite these shortcomings, the present study offers several unique findings in the area of attention-based coping strategies for pain in children, as well as in the use of mindfulness-based interventions with children. Overall, the present study provides preliminary evidence that children older than 10 years of age may be able to mindfully devote attention to acute pain if given brief instructions on how to do so. Furthermore, children asked to mindfully devote attention to pain did not differ significantly with regard to pain outcomes compared with children who received a well-established intervention for acute pain, and the effectiveness of these interventions was not dependent on baseline characteristics. The finding that the mindful attention instructions increased attention to the physical sensations and thoughts about those sensations during the CPT without increasing pain intensity or decreasing pain tolerance is particularly interesting, given that some authors have argued that it may be necessary for individuals to engage in regular mindfulness practice to take a more accepting attitude toward aversive internal experiences (19). However, we have found that a brief set of mindful attention instructions help children attend to this experience in a way that does not increase pain outcomes. This is also encouraging for health care professionals interested in incorporating mindfulness-based intervention into treatment for children with chronic pain, in that it suggests that the inclusion of mindful attention may provide similar benefits to distraction-based interventions that are typically included in cognitive behavioural therapy protocols for chronic pain (8). This may be especially important when working with children who do not find distraction to be an effective intervention. It also demonstrates that individuals interested in using mindfulness interventions for children with chronic pain can do so without great concern that having children attend to pain mindfully will increase pain. However, more research is required to help understand when these interventions that help focus attention on pain in a more adaptive manner will be most effective.

ACKNOWLEDGEMENTS: The authors thank Jennifer Parker for her help in all administrative aspects of the study, as well as final edits; Melanie Noel for her help and enthusiasm in recruiting participants; and research assistants Bryanne Harris, Laura Slauenwhite and Molly Williamson for guiding participants and assisting with data cleaning.

FUNDING AND CONFLICTS OF INTEREST: This project was supported by a Canadian Institutes of Health Research Doctoral Award, a Killam Predoctoral Scholarship and an IWK Health Centre Category A Research Grant awarded to Mark Petter. Mr. Petter is also a trainee member of Pain in Child Health, a strategic research training initiative of the Canadian Institutes of Health Research. This research was also supported by a Canada Research Chair, a Canadian Institutes of Health Research Operating Grant, and a Canada Foundation for Innovation grant awarded to Christine Chambers. The authors have no conflicts of interest to declare regarding the present study.

\section{REFERENCES}

1. Powers SW. Empirically supported treatments in pediatric psychology: Procedure-related pain. J Pediatr Psychol 1999;24:131-45.

2. Fanurik D, Zeltzer LK, Roberts MC, Blount RL. The relationship between children's coping styles and psychological interventions for cold pressor pain. Pain 1993;53:213-22.

3. Piira T, Hayes B, Goodenough B, von Baeyer CL. Effects of attentional direction, age, and coping style on cold-pressor pain in children. Behav Res Ther 2006;44:835-48.

4. Uman LS, Chambers CT, McGrath PJ, Kisely S. Psychological interventions for needle-related procedural pain and distress in children and adolescents. Cochrane Database Syst Rev 2006(4):CD005179.

5. Uman LS, Chambers CT, McGrath PJ, Kisely S. A systematic review of randomized controlled trials examining psychological interventions for needle-related procedural pain and distress in children and adolescents: An abbreviated Cochrane review. J Pediatr Psychol 2008;33:842-54.

6. Tanabe P, Ferket K, Thomas R, Paice J, Marcantonio R. The effect of standard care, ibuprofen, and distraction on pain relief and patient satisfaction in children with musculoskeletal trauma. J Emerg Nurs 2002;28:118-25.

7. Walker LS, Williams SE, Smith CA, Garber J, Van Slyke DA, Lipania TA. Parent attention versus distraction: Impact on symptom complaints by children with and without chronic functional abdominal pain. Pain 2006;122:43-52. 
8. Noel M, Petter M, Parker JA, Chambers CT. Cognitive-behavioural therapy for pediatric chronic pain: The problem, research, and practice. J Cogn Psycother 2012;25:143-56.

9. Chambers CT, Taddio A, Uman LS, McMurtry CM, HELPinKIDS Team. Psychological interventions for reducing pain and distress during routine childhood immunizations: A systematic review. Clin Ther 2009;31:S77-S103.

10. Verhoeven K, Goubert L, Jaaniste T, Van Ryckeghem DM, Crombez G. Pain catastrophizing influences the use and the effectiveness of distraction in school children. Eur J Pain 2012;16:256-67.

11. Auerbach SM, Kendall PC, Cuttler HF, Levitt NR. Anxiety, locus of control, type of preparatory information, and adjustment to dental surgery. J Consult Clin Psychol 1976;44:809-18.

12. Leventhal H, Brown D, Shacham S, Engquist G. Effects of preparatory information about sensations, threat of pain, and attention on cold pressor distress. J Pers Soc Psychol 1979;37:688-714.

13. Kabat-Zinn J. Full Catastrophe Living: How to Cope with Stress, Pain and Illness Using Mindfulness Meditation. London: Piatkus, 1996.

14. Bishop SR, Lau M, Shapiro S, et al. Mindfulness: A proposed operational definition. Clin Psychol Sci Pract 2004;11:230-41.

15. Shapiro SL, Carlson LE, Astin JA, Freedman B. Mechanisms of mindfulness. J Clin Psychol 2006;62:373-86.

16. Grossman P, Niemann L, Schmidt S, Walach H. Mindfulness-based stress reduction and health benefits. A meta-analysis. J Psychosom Res 2004;57:35-43.

17. Zeidan F, Gordon NS, Merchant J, Goolkasian P. The effects of brief mindfulness meditation training on experimentally induced pain. J Pain 2010;11:199-209.

18. Kingston J, Chadwick P, Meron D, Skinner TC. A pilot randomized control trial investigating the effect of mindfulness practice on pain tolerance, psychological well-being, and physiological activity. J Psychosom Res 2007;62:297-300.
19. Thompson M, Gauntlett-Gilbert J. Mindfulness with children and adolescents: Effective clinical application. Clin Child Psychol Psychiatry 2008;13:395-407.

20. Grewal S, Petter M, Feinstein AB. The use of distraction, acceptance, and mindfulness-based techniques in the treatment of pediatric pain. Ped Pain Letter 2012;14:1-9.

21. Campbell CM, Kronfli T, Buevaner LF, et al. Situational versus dispositional measurement of catastrophizing: Associations with pain responses in multiple samples. J Pain 2010;11:443-53.

22. Birnie KA, Noel M, Chambers CT, von Baeyer CL, Fernandez CV. The cold pressor task: Is it an ethically acceptable pain research method in children? J Pediatr Psychol 2010;36:1071-81.

23. von Baeyer CL, Piira T, Chambers CT, Trapanotto M, Zeltzer LK. Guidelines for the cold pressor task as an experimental pain stimulus for use with children. J Pain 2005;6:218-27.

24. Reid GJ, Gilbert CA, McGrath PJ. The pain coping questionnaire: Preliminary validation. Pain 1998;76:83-96.

25. Greco LA, Baer RA, Smith GT. Assessing mindfulness in children and adolescents: Development and validation of the child and adolescent mindfulness measure (CAMM). Psychol Assess 2011;23:606-14.

26. Hicks CL, von Baeyer CL, Spafford PA, van Korlaar I, Goodenough B. The faces pain scale - revised: Toward a common metric in pediatric pain measurement. Pain 2001;93:173-83.

27. Enders CK. A primer on maximum likelihood algorithms available for use with missing data. Struct Equ Model 2001;8:128-41.

28. Grabovac AD, Lau MA, Willett BR. Mechanisms of mindfulness: A Buddhist psychological model. Mindfulness 2011;2:154-66.

29. Von Baeyer CL, Torvi D, Hemingson H, Beriault D. Water circulation and turbulence in the cold pressor task: Unexplored sources of variance among experimental pain laboratories. Ped Pain Letter 2011;13:13-6. 


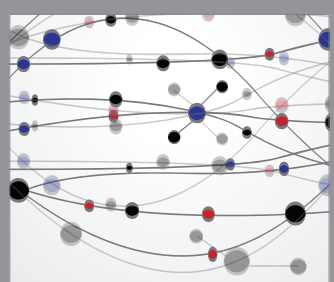

The Scientific World Journal
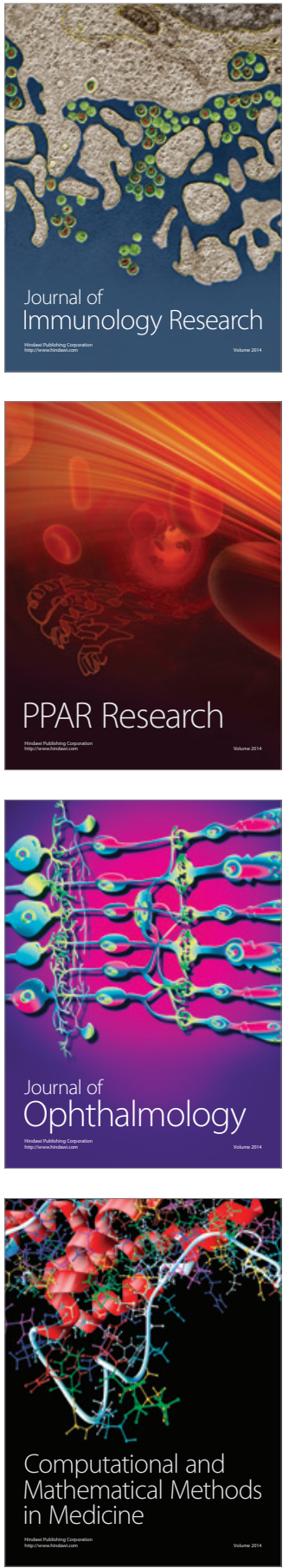

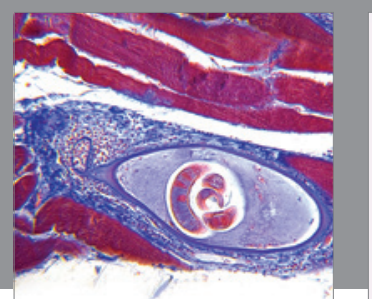

Gastroenterology Research and Practice

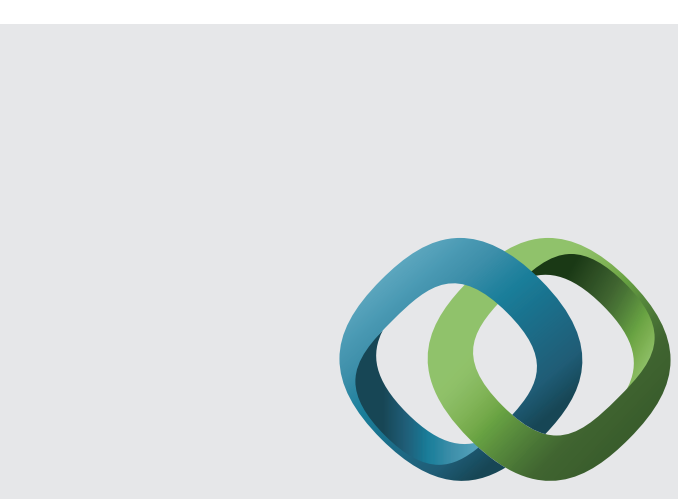

\section{Hindawi}

Submit your manuscripts at

http://www.hindawi.com
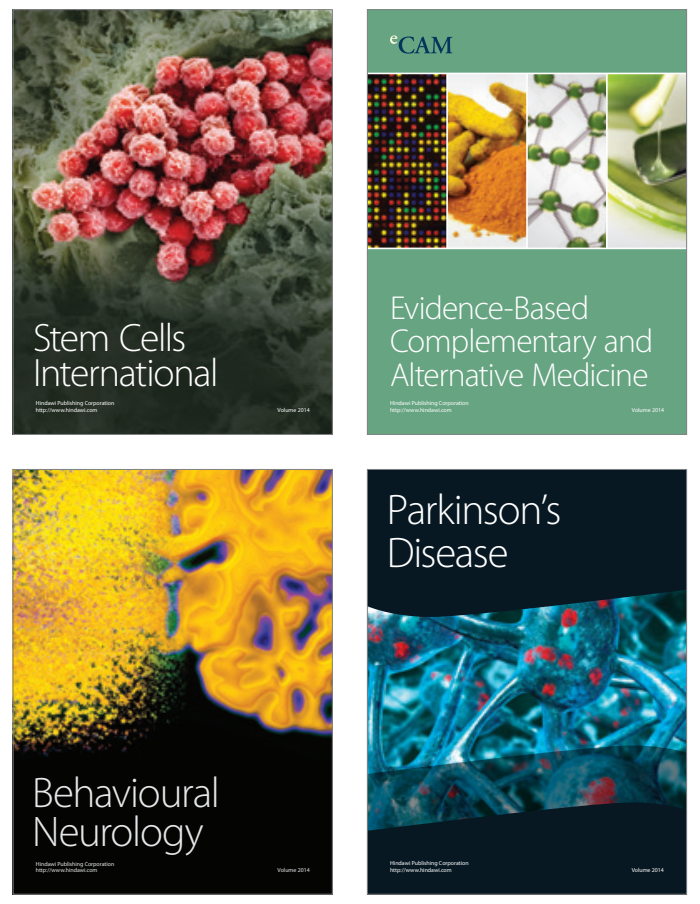
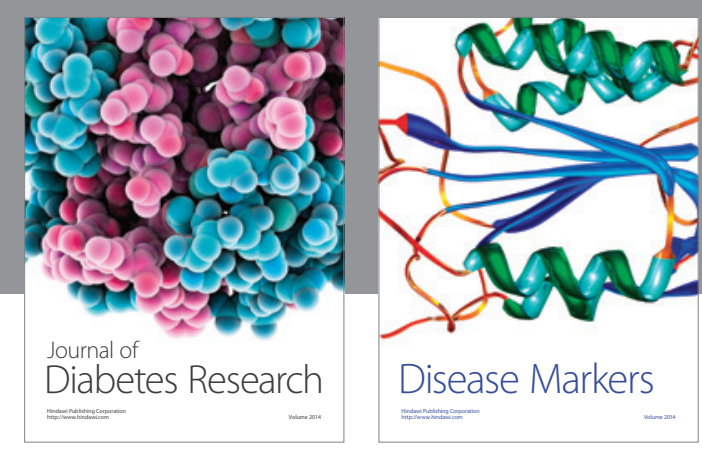

Disease Markers
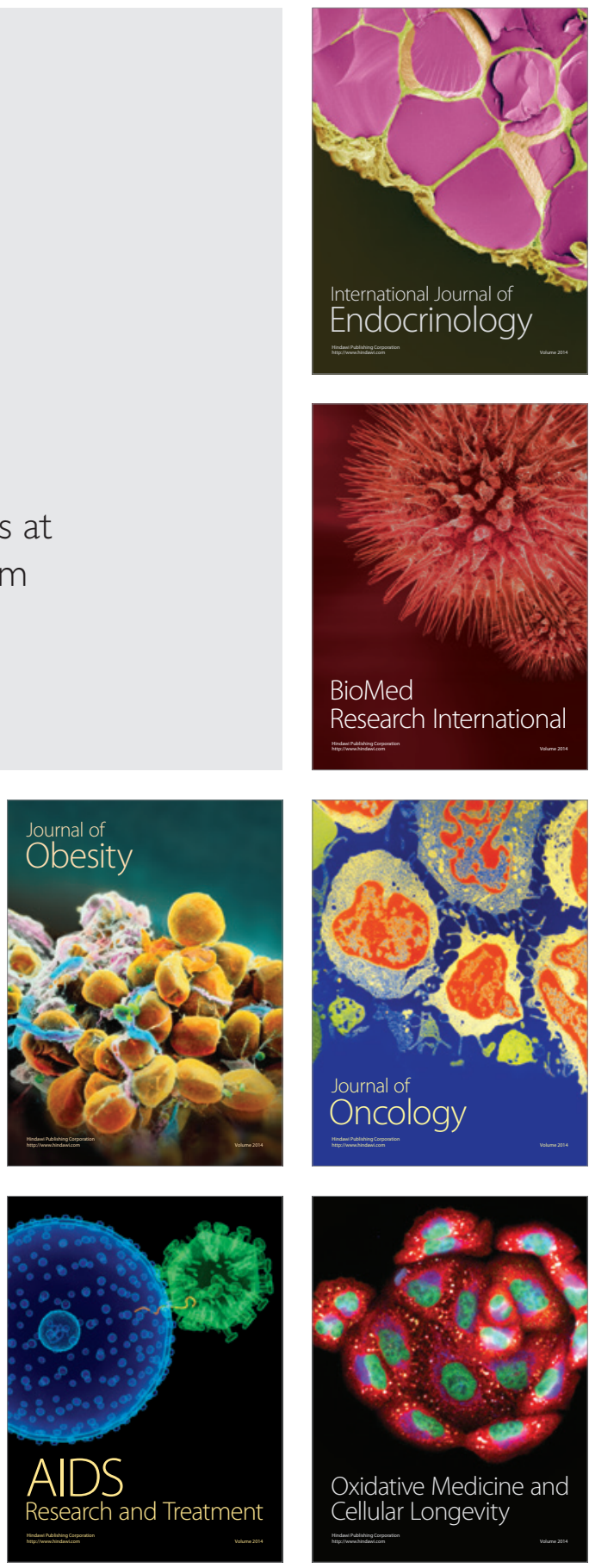